Indexed by

\title{
OPTIMIZATION OF POWDER COATING PROCESS PARAMETERS IN MILD STEEL (SPCC-SD) TO IMPROVE DRY FILM THICKNESS
}

\section{Sukarman}

Sekolah Tinggi Teknologi

Wastukancana, Mechanical

Engineering Department,

Purwakarta, Indonesia

\section{Nana Rahdiana}

Universitas Buana Perjuangan

Karawang, Industrial

Engineering Department,

Karawang, Indonesia
Apang Djafar Shieddieque

Sekolah Tinggi Teknologi

Wastukancana, Mechanical

Engineering Department,

Purwakarta, Indonesia

\section{Anwar Ilmar Ramadhan}

Universitas Muhammadiyah

Jakarta, Faculty of Engineering,

Mechanical Engineering

Department,

Jakarta, Indonesia
Choirul Anwar

Sekolah Tinggi Teknologi

Wastukancana, Mechanical

Engineering Department,

Purwakarta, Indonesia

Key words: powder coating, Taguchi method, S/N ratio, dry film thickness, epoxy-polyester

Cite article:

Sukarman, Apang, D. S., Choirul, A., Nana, R., \& Anwar, I. R. [2021]. Optimization of powder coating process parameters in mild steel (spcc-sd) to improve dry film thickness. Journal of Applied Engineering Science, 19(2), 475 - 482. DOl:10.5937/jaes0-26093

Online aceess of full paper is available at: www.engineeringscience.rs/browse-issues 


\title{
OPTIMIZATION OF POWDER COATING PROCESS PARAMETERS IN MILD STEEL (SPCC-SD) TO IMPROVE DRY FILM THICKNESS
}

\author{
Sukarman ${ }^{1 *}$, Apang Djafar Shieddieque', Choirul Anwar', Nana Rahdiana ${ }^{2}$, Anwar Ilmar Ramadhan ${ }^{3}$ \\ 'Sekolah Tinggi Teknologi Wastukancana, Mechanical Engineering Department, Purwakarta, Indonesia \\ ${ }^{2}$ Universitas Buana Perjuangan Karawang, Industrial Engineering Department, Karawang, Indonesia \\ ${ }^{3}$ Universitas Muhammadiyah Jakarta, Faculty of Engineering, Mechanical Engineering Department, Jakarta, \\ Indonesia
}

This study presents a comprehensive review of the improved optimization for powder coating process variables in mild steel (SPCC-SD). The effective thickness of the dry film thickness (DFT) keeps a significant influence on the critical protection of mild steel against rust. In the powder coating process, the variable thickness is one of the primary and difficult objectives to accurately control the desired consistency. This empirical study properly uses RAL 7040 epoxy-polyester with the required thickness between 70-100 microns. This empirical study aims to reasonably achieve the optimal value of the effective thickness of the powder layer from specific combinations of specified process criteria. Practical experiments were properly conducted out manipulating an orthogonal Taguchi L16 array of independent variables; program, distance, application method, and the number of layers. This optimization method has been successfully upgraded. The average thickness of the powder coating layers reaches 84.85 microns. For a given limit, the application-method of typically preventing the determined cause correctly examined efficiently provides the most significant effect on effective thickness with an S/N ratio of 0.91. In the future, the relevant research may use our corresponding results to improve the powder coating procedure for other significant impacts.

Key words: powder coating, Taguchi method, S/N ratio, dry film thickness, epoxy-polyester

\section{INTRODUCTION}

Nowadays the scientifically many research requests in the industrial field of powder coating. That was a reasonable request because powder coatings are increasingly popular and successful on the commercial side. Powder coatings present several comparative advantages, including little or no volatile organic compounds (VOC), high usage, energy savings and effective elimination of hazardous waste [1-4]. From the regulation point of practical view, it also properly reasonably doesn't use volatile organic compounds (VOC) coatings. REACH (Registration, Evaluation, and Authorization \& Restriction of Chemicals) regulations have intentionally limited conventional organic coatings. For the typical example of organic coating such hydrocarbons (hexane, toluene, xylene), used alcohols (Methanol, ethanol, and cyclohexane), and esters (ethyl acetate, butyl acetate) isobutyl acetate). Ketones (acetone, MEK, MIBK) [5]. The modern powder coating correctly is a $100 \%$ solid coating which is applied as a dry powder and then made into a dry film thickness by heating. The application method is properly used solid binders and pigments [6-9]. Standardly, there typically have two standard types of powder coating, namely thermoplastic and thermosetting powders [10-14].

The empirical research on the continuous optimization of the powder coating process has not been done much. Zouari et al, (2015), has meaningfully improved coating properties related to scratch resistance and typically wears to typically prevent the potential severity of the potential damage. The empirical study was carried out properly by properly comparing the polyester composite and epoxy layers which were added $5 \%$ MoS2 each. The published results typically showed that an epoxy composite layer reinforced with $5 \%$ by used weight of MoS2. It properly had a better scratch resistance response inevitably compared to polyester composite reinforced with $5 \%$ by the optimal weight of MoS2 [15]. The effective Taguchi method has been widely practiced in many fabrication processes.

The past researchers, has properly implemented this effective method of continuous optimization of the Tube Hydroforming Process (THP). This empirical research properly implemented the effective Taguchi method of four standard parameters and three practical levels of the practical experiment. This practical result was accurately experienced that the die corners radius, a considerable length and variable thickness of the used tube are significantly affecting the process [16]. Thakur et al, 2014, has properly practiced this effective method of continuous optimization of the resistance spot welding (RSW) process. This empirical research carried out the continuous optimization of RSW process parameters for galvanized steel sheet material. This focused study properly used the standard Taguchi method of six measurable parameters and three specific levels of the practical experiment. RSW process parameter analysis was satisfactorily performed using ANOVA. From the experimental results 
was properly known that the most significant parameters critically affect the nominal strength of the direct connection are the welding current and welding time, while the squeeze time and hold time parameters correctly are less significant factors [17-21].

Unlike previous studies, this empirical study properly used the standard Taguchi method to improve the powder coating process. This empirical study using four variables and two practical levels of design of experiments. The practical experiments were carried out using orthogonal L16 Taguchi arrays. The variable used programs, standard distances, application methods and the determined number of specific layers. This study aims to correctly influence the most exceptional value of the powder coating thickness from the specific combination of process parameters.

\section{METHODOLOGY}

\section{Experimental setup}

Before the practical experiment correctly begins, all specific conditions of the proper equipment have carefully to appropriately follow safety regulations. The specific condition of the test set should be properly checked and promptly confirmed to suitably meet the safety requirements. This experimental study rightly used the OptiStar CGO7 spray gun with a nominal capacity of $100 \mathrm{~W}$ and $110 / 220$ VAC vibrator connection. The program parameters that will be used in this practical experiment are power output (\%), Fluidizing display, spray current and high voltage. The adjustable parameters for each specific program are properly presented in Table 1.

Table 1: Spray gun experimental setup

\begin{tabular}{|c|c|c|}
\hline Parameters setting & P01 & P02 \\
\hline Powder output $(\%)$ & 65 & 65 \\
\hline Fluidizing $\left(\mathrm{Nm}^{3} / \mathrm{h}\right)$ & 46 & 46 \\
\hline Spray current $(\mu \mathrm{A})$ & 22 & 21 \\
\hline High voltage $(\mathrm{kV})$ & 44 & 52 \\
\hline
\end{tabular}

The spray gun setup is done through the "Gun control unit". This research uses program 01 (P01) and program 02 (P02). The four parameters of the spray gun are set up in two programs, P01, and P02. The lower setting/ level-1 used program P01 and the higher setting/level-2 used program P02. The results of spray gun settings in P01 and P02 are presented in the following Figure 1.
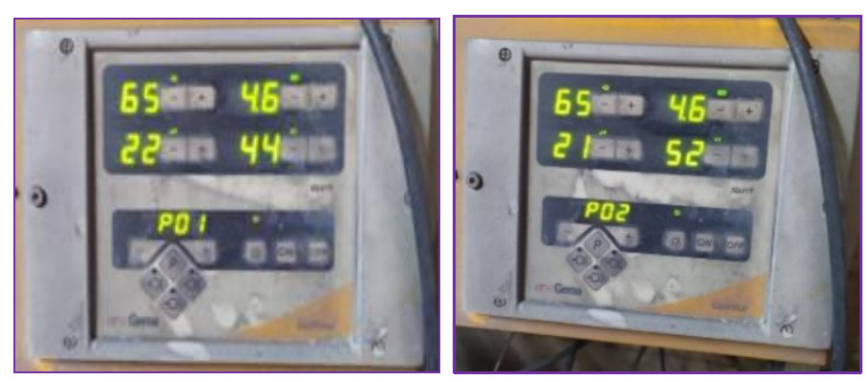

Figure 1: P01 and P02 programs in spray gun control unit
Schematic powder coating system in this study applied to Figure 2.

Powder coating in this study applied to SPCC-SD plates measuring $375 \mathrm{~mm} \times 300 \mathrm{~mm}$. The thickness coating measured at five locations. The measuring point is shown in the Figure 3.

The mechanical properties and chemical composition according to JIS 3141 are given in Table 2 and Table 3.

The type of powder coating material used in research is RAL 7040 epoxy-polyester. This material has passed the

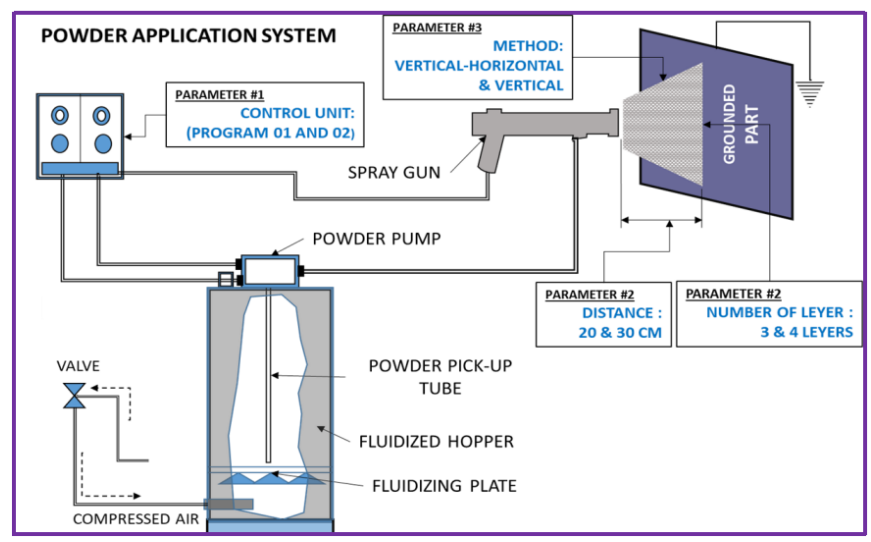

Figure 2: Powder application system

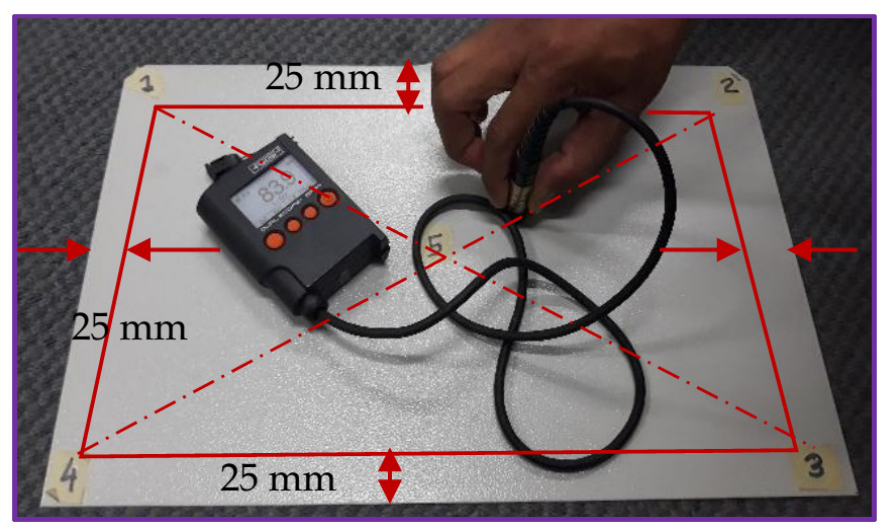

Figure 3: The coating thickness measurement procedure

Table 2: Mechanical properties and coating weight [5]

\begin{tabular}{|c|c|c|}
\hline SECC-AF & JIS 3141 & Coil No. CPW6629C \\
\hline YP (N/mm2) & $240 \mathrm{max}$. & 229 \\
\hline TS (N/mm2) & $270 \mathrm{~min}$. & 329 \\
\hline $\mathrm{EL}(\%)$ & $37 \mathrm{~min}$. & \\
\hline
\end{tabular}

Table 3: Chemical composition (\%) [5]

\begin{tabular}{|c|c|c|}
\hline SECC-AF & JIS 3141 & Coil No. CPW6629C \\
\hline $\mathrm{C}$ & 0.15 max. & 0.0196. \\
\hline $\mathrm{Mn}$ & 0.05 max. & 0.2040 \\
\hline $\mathrm{P}$ & 0.04 max. & 0.0010 \\
\hline $\mathrm{S}$ & 0.04 max. & 0.0030 \\
\hline
\end{tabular}

Istraživanja i projektovanja za privredu ISSN 1451-4117 Journal of Applied Engineering Science Vol. 19, No. 2, 2021 
corrosion test of corrosion in 500 hours. The testing process used the ASTM B117 salt spray corrosion test standard and evaluated using the ASTM D 1654 (Rating of Failure at Scribe (Procedure A) standard). This material has a rust resistance rating of 9 (scale $0-10)$, higher the value will have a better rust resistance. Powder coating specifications illustrated Table 4.

Table 4: Specification of RAL 7040 epoxy-polyester powder

\begin{tabular}{|c|c|c|}
\hline Parameters & Spec. & Batch 20000584 \\
\hline Colour & R-7040 & R-7040 \\
\hline Deviation $\Delta \mathrm{E}$ & Max. 0.5 & 0.3 \\
\hline Hardness & Min. H & $2 \mathrm{H}$ \\
\hline Gloss, 60 degree & $20 \%+/-5$ & $23 \%$ \\
\hline Adhesion (at 2 mm) & Gt. 0 & Gt. 0 \\
\hline Corrosion creep & $\geq$ Rating 6 & Rating 9 \\
\hline Particle Size: & & \\
\hline$\bullet>80 \mu \mathrm{m}$ & $<40 \%$ & $15.00 \%$ \\
$\bullet>20 \mu \mathrm{m}$ & $<75 \%$ & $64.00 \%$ \\
\hline
\end{tabular}

Measuring instruments used in this study are shown in Table 5.

Table 5: The summary for the uncertainties of the experimental parameters

\begin{tabular}{|c|c|c|}
\hline Parameters setting & Full scale & Accuracy \\
\hline $\begin{array}{c}\text { Coating Thickness Gauge } \\
(\mu \mathrm{m})\end{array}$ & $0-2000$ & $1.5-3 \%$ \\
\hline Oven Data logger $\left({ }^{\circ} \mathrm{C}\right)$ & $-50-1200$ & 0.1 \\
\hline Measuring tape $(\mathrm{mm})$ & 4000 & 1 \\
\hline Digital Multimeter $(\mathrm{A})$ & 5000 & $1 \%$ \\
\hline
\end{tabular}

\section{Powder coating parameter selection}

Powder coating variables were identified to predict the coating characteristics of thickness coating. These variables included independently controllable powder coating process parameters namely, programs, distances, application methods, and the number of layers. The level of each process parameter was chosen in an available range of powder coating (Table 6). In the powder coating process, the surface treatments of base metal, baking oven profiling, and grounding system were important to control. Therefore, five repetitions (R1, R2, R3, R4, and $\mathrm{R} 5)$ for each trial were selected as the noise factor of this experimental arrangement.

\section{Signal to noise ratio-S/N ratio}

In this experiment, 16 randomized trials based on OA (orthogonal array L16) were conducted. Five responses were taken for each the set. Powder coating parameters were varied from each given level (Table 7). Because rust resistance is directly proportional to the thickness of
Table 6: Process parameter with their values at different levels

\begin{tabular}{|c|c|c|c|}
\hline \multirow{2}{*}{ Code } & \multirow{2}{*}{ Factors } & \multicolumn{2}{|c|}{ Level } \\
\cline { 3 - 4 } & & 1 & 2 \\
\hline A & Programs & P01 & P02 \\
\hline B & Distance $(\mathrm{cm})$ & 20 & 30 \\
\hline C & Method & Vertical & Vertical-Horizontal \\
\hline D & $\begin{array}{c}\text { The numbers of } \\
\text { layer (cycles) }\end{array}$ & 4 & 3 \\
\hline
\end{tabular}

the film, so the maximum thickness value is the expected target response. Its mean calculation of the Signal to Noise (SN Ratio) will be performed with the characteristics of larger is better. The Taguchi method uses signal to noise $(\mathrm{S} / \mathrm{N})$ ratio, which indicates the desired sensitivity of the input factor. Optimal conditions are achieved by defining the effects of each input factor and measurable characteristics with a positive value and is based on means and standard deviations. Achieving higher grades indicates better quality [9]. The formula used to calculate the characteristic S/N ratio is shown in the following equation (1) [8].

$S N R=-\log \left(\frac{1}{N} \sum_{l=1}^{N} \frac{1}{T_{l}^{2}}\right)$

Where $T$, thickness coating in $\mu$.

\section{Orthogonal array (OA)}

Orthogonal arrays (OA) typically consume a matrix to ensure a balanced level comparison of any critical factor. The Orthogonal arrays (OA) used a matrix typically consumed to accurately determine the selected sample of the specific group. The used matrix typically allows us to accurately determine the standard specifications for the sample group efficiently produced. The OA matrix determination typically based on the prime number of essential factors. The practical levels typically used for empirical research. In this empirical study, each key factor is used in the two levels of experiments. It was accurately detected that for this empirical study the OA in contrast $\left(2^{* *} 15\right)$ Array. Four two-level control factors were considered in this work. The four control factors yield 7 degrees of freedom. The L12 OA that has 11 degrees of freedom was selected in this work as shown in Table 7 by [7] [8].

Multiple linear regression models are developed for average thickness of powder coating and $\mathrm{S} / \mathrm{N}$ ratio by using statistical software. The response variable are average thickness of powder coating and $\mathrm{S} / \mathrm{N}$ ratio whereas the predictors are A-Programs, B-Distance, C-Method and D-Number of layers. The experimental results are used to model the response using Taguchi design [1]. The regression equation of the fitted model for average thickness of powder coating, Mean $(\mu \mathrm{m})$;

$M E A N_{\text {pred. }}=8.92-21.91 A-1.755 B+18.67 C+1.83 A B-8.92 A C$ 
Table 7: Experimental data for thickness of powder coating and S/N ratio

\begin{tabular}{|c|c|c|c|c|c|c|c|c|c|c|c|c|c|}
\hline \multirow{2}{*}{ Iterations No. } & \multicolumn{4}{|c|}{$\begin{array}{c}\text { Process } \\
\text { parameters }\end{array}$} & \multicolumn{5}{|c|}{ Thickness of powder coating in $\mu \mathrm{m}(\mathrm{T})$} & \multicolumn{2}{|c|}{$\begin{array}{c}\text { Average Thickness in } \\
\mu \mathrm{m}(\mathrm{T})\end{array}$} & \multicolumn{2}{|c|}{$\mathrm{S} / \mathrm{N}$ ratio } \\
\hline & $A$ & $\mathrm{~B}$ & C & $\mathrm{D}$ & $\mathrm{R} 1$ & $\mathrm{R} 2$ & R3 & R4 & R5 & Exp. $^{*}$ & Pred. ${ }^{* *}$ & Exp. $^{*}$ & Pred. ** \\
\hline 1 & 1 & 1 & 1 & 1 & 61.01 & 61.52 & 72.10 & 57.22 & 60.20 & 62.41 & 66.33 & 35.83 & 36.17 \\
\hline 2 & 1 & 1 & 1 & 2 & 50.35 & 67.95 & 69.64 & 80.86 & 46.64 & 63.09 & 66.33 & 35.44 & 36.17 \\
\hline 3 & 1 & 1 & 2 & 1 & 60.92 & 80.30 & 62.00 & 80.70 & 74.60 & 71.70 & 76.08 & 36.91 & 37.08 \\
\hline 4 & 1 & 1 & 2 & 2 & 72.30 & 71.58 & 96.66 & 99.80 & 91.10 & 84.85 & 76.08 & 38.32 & 37.08 \\
\hline 5 & 1 & 2 & 1 & 1 & 57.62 & 59.63 & 80.30 & 65.98 & 48.28 & 62.36 & 60.61 & 35.54 & 35.23 \\
\hline 6 & 1 & 2 & 1 & 2 & 58.80 & 45.18 & 74.71 & 91.57 & 45.90 & 63.23 & 60.61 & 35.08 & 35.23 \\
\hline 7 & 1 & 2 & 2 & 1 & 58.16 & 71.42 & 59.81 & 81.14 & 58.46 & 65.80 & 70.36 & 36.14 & 36.13 \\
\hline 8 & 1 & 2 & 2 & 2 & 78.70 & 58.92 & 91.16 & 47.35 & 62.71 & 67.77 & 70.36 & 35.95 & 36.13 \\
\hline 9 & 2 & 1 & 1 & 1 & 68.48 & 54.31 & 60.50 & 60.40 & 50.24 & 58.79 & 59.17 & 35.24 & 34.42 \\
\hline 10 & 2 & 1 & 1 & 2 & 58.64 & 70.99 & 48.50 & 97.41 & 34.12 & 61.93 & 59.17 & 34.25 & 34.42 \\
\hline 11 & 2 & 1 & 2 & 1 & 66.20 & 52.89 & 62.00 & 54.20 & 57.80 & 58.62 & 60.00 & \begin{tabular}{|l|}
35.27 \\
\end{tabular} & 35.32 \\
\hline 12 & 2 & 1 & 2 & 2 & 65.00 & 54.27 & 60.30 & 41.83 & 60.20 & 56.32 & 60.00 & 34.69 & 35.32 \\
\hline 13 & 2 & 2 & 1 & 1 & 59.63 & 80.30 & 65.98 & 57.62 & 57.63 & 64.23 & 65.28 & 35.96 & 35.33 \\
\hline 14 & 2 & 2 & 1 & 2 & 45.18 & 74.71 & 78.90 & 64.20 & 43.18 & 61.23 & 65.28 & 34.93 & 35.33 \\
\hline 15 & 2 & 2 & 2 & 1 & 71.42 & 59.81 & 81.14 & 58.16 & 69.42 & 67.99 & 66.11 & 36.46 & 36.24 \\
\hline 16 & 2 & 2 & 2 & 2 & 58.92 & 91.16 & 47.35 & 78.70 & 56.92 & 66.61 & 66.11 & 35.77 & 36.24 \\
\hline
\end{tabular}

And the regression equation of the fitted model for $\mathrm{S} / \mathrm{N}$ ratio;

$$
S N R_{\text {pred. }}=42.64-5.48 A-0.2807 B+0.906 C+1.861 A B
$$

\section{RESULTS AND DISCUSSION}

\section{$\mathrm{S} / \mathrm{N}$ ratio analysis}

The Taguchi method uses the signal to noise ratio $(\mathrm{S} / \mathrm{N})$, which shows the sensitivity of the characteristics needed for factor input, in a controlled process. Optimal conditions are generated by each of the input factors of the output characteristics. The purpose of $\mathrm{S} / \mathrm{N}$ ratio analysis is to determine the exact level of different inputs to achieve the best response. $\mathrm{S} / \mathrm{N}$ ratio response graph for the average powder thickness data presented in Figure 4.

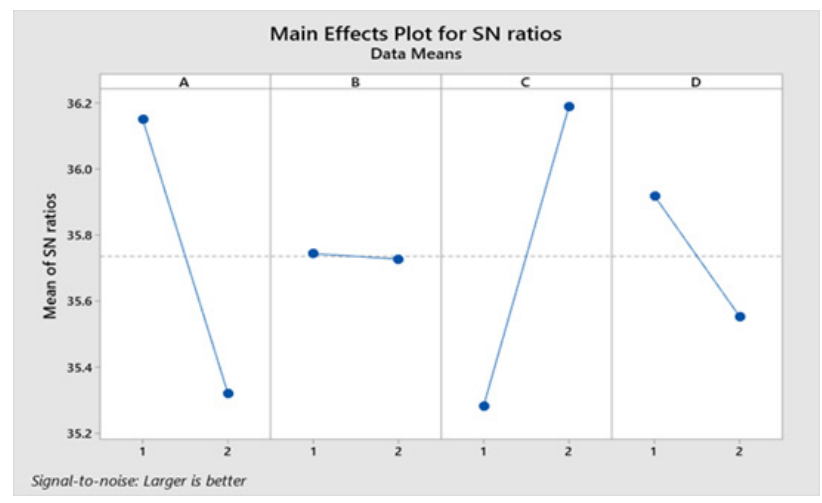

Figure 4: Main effects plot of signal-to-noise ratio for program, distance, method, No. of Layer based on thickness measurement response
The data above is directly proportional to the average thickness of powder coating thickness. Figure 4 shown that the highest average data is reached when using the program, distance and number of layer parameters at the first level, and the method at the second level. Because using the $S / N$ ratio approach from larger is better characteristics, the program parameter $(A)$, it seems that the P01 program has a higher response effect compared to the P02 program. With another approach, it can be said that the program at level 1 significantly influences the thickness of the powder coating response compared to level 2 programs. The $\mathrm{S} / \mathrm{N}$ ratio values of level 1 and 2 programs are 36.15 and 35.32 , respectively.

For the spray distance parameter (A), it can be seen on the graph that a $30-\mathrm{cm}$ distance has a lower response effect than a $20-\mathrm{cm}$ distance. It can also be mentioned that the spray spacing at level 1 has a more significant effect on the thickness of the powder coating response than level 2. S/N ratios of level 1 and 2 distance parameters are 35.74 and 35.73 , respectively. For the application method parameters $(C)$ seen in the graph that the vertical-horizontal method has a higher response effect compared to the vertical method. This condition can be explained that the method of level 2 has more significantly influenced the powder coating thickness response compared to level 1 . The $\mathrm{S} / \mathrm{N}$ ratio values for both methods of levels 1 and 2 are 35.28 and 36.19 , respectively. For the number of layer parameters, Fig. 4 shows that the number of layers 3 has a higher response effect to DFT. It can also be said that the number of layer parameters at level 1 slightly has significantly influenced the 
response. DFT compared to level 2 . The $\mathrm{S} / \mathrm{N}$ ratio values for both methods of levels 1 and 2 are 35.92 and 35.55, respectively. The method parameter has the highest S/N response to 0.91 . From this data, it can be explained that the method has significant parameters that affect to a thickness of the powder layer. The variable responses from the powder coating are examined in Table 8.

Response data for the standard deviation of the powder coating thickness at each determined level of the typical experiment are sufficiently shown in Table 9.

Table 8: Response for Signal to Noise Ratios

\begin{tabular}{|c|c|c|c|c|}
\hline Level & Program & Distance & Method & No. of Layer \\
\hline 1 & 36.15 & 35.74 & 35.28 & 35.92 \\
\hline 2 & 35.32 & 35.73 & 36.19 & 35.55 \\
\hline Delta & 0.83 & 0.02 & 0.91 & 0.37 \\
\hline Rank & 2 & 4 & 1 & 3 \\
\hline
\end{tabular}

Table 9: Response for standard deviations

\begin{tabular}{|c|c|c|c|c|}
\hline Level & Program & Distance & Method & No. of Layer \\
\hline S/N 1 & 12.747 & 11.029 & 13.591 & 8.602 \\
\hline S/N 2 & 12.338 & 14.056 & 11.494 & 16.483 \\
\hline Delta & 0,1408 & 3.027 & 2.097 & 2.097 \\
\hline Rank & 4 & 2 & 3 & 1 \\
\hline
\end{tabular}

In meaningful statistics, the standard deviation is a measure of the substantial amount of observed variation or dispersion of a specific set of optimal values. The smaller standard deviation correctly is the better the observed variation of the qualitative data. Table 9 shows that the program variables typically have the lowest standard deviation which typically shows the observed data in the program variables is the best.

\section{Interaction plot parameters}

Interaction between factors occurs when the change in response from low to higher levels of one factor is not the same as the change in response at the two levels of the same second factor. That is, the effect of one factor depends on the second factor. An interaction plot can be used to compare the relative strengths of the effects of factors. An intersection plot can also be used to see the combined interaction of response variables, namely by looking at the graph intersection of each parameter measured. The intersection of the graphs with each other indicates the interaction for each other showed Figure 5.

Figure 5 shown the interaction between program and distance $\left(A^{*} B\right)$, programs and the method $\left(A^{*} C\right)$, programs by number of layers" $\left(A^{*} D\right)$, the distance by the method $\left(B^{*} C\right)$, the distance by the number of layers $\left(B^{*} D\right)$ and methods by the number of layers $\left(C^{*} D\right)$. The interaction plot of mean showed that interactions have significantly affected the response is program and distance $\left(A^{*} B\right)$, programs and the method $\left(A^{*} C\right)$, programs by number

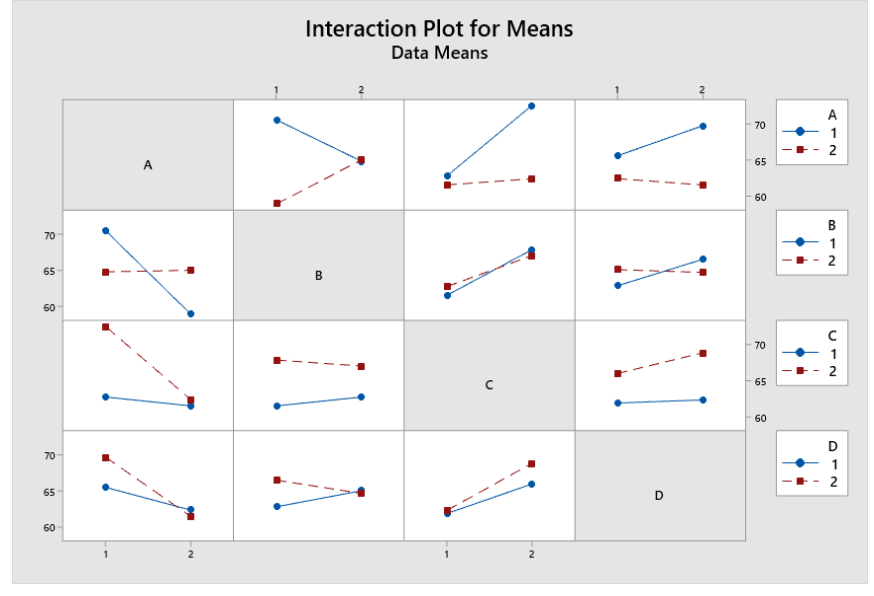

Figure 5: Interaction plot for data mean

of layers" $\left(A^{*} D\right)$, the distance by the method $\left(B^{*} C\right)$, and distance by the number of layers $\left(B^{*} D\right)$. It can be seen from the intersection of the two graphs on each parameter, which intersect with each other. While and methods by the number of layers $\left(C^{*} D\right)$ have not significantly affected the response variable (variable thickness of paint powder). This condition can be seen from the absence of the intersection of the two-parameter graphs. Interactions between parameters can be explained as follows:

- Interaction plot of $A^{*} B$ (program $x$ distance).

The practical application of program 01 at a reasonable distance of $20-\mathrm{cm}$ to $30-\mathrm{cm}$ will typically reduce the thickness response. This is inversely proportional to program 02. In the application program 02 a marked increase in the effective thickness of the powder coating response at a used distance of $30 \mathrm{~cm}$.

- Interaction plot of $A^{*} C$ (program $x$ method)

The practical application of program 01 and 02 in the vertical-horizontal to vertical method has typically increased the thickness response.

- Interaction plot of $A^{*} D$ (program $x$ number of layers). The practical application of program 01 and program 02 during direct applications 3 and 4 layers experienced a significant increase in thickness response.

- Interaction plot of $\mathrm{B}^{*} \mathrm{C}$ (distance $\mathrm{x}$ method)

Practical applications in $20 \mathrm{~cm}$ and $30 \mathrm{~cm}$ distance parameter have generally increased thickness response in the vertical-horizontal method application.

- Interaction plot of $B^{*} \mathrm{D}$ (distance $\mathrm{x}$ number of layers) The practical application of the $30 \mathrm{~cm}$ distance parameter typically has a significant increase in thickness response to the level increase of the layer parameter. In the $20 \mathrm{~cm}$ distance parameter, the marked decrease in thickness response that particularly occurs is not significant enough.

\section{Analysis of variance (ANOVA)}

The ANOVA is a statistical technique that quantitatively determines the contribution to the total variation, which is 
Table 10: Analysis of variance for means

\begin{tabular}{|c|c|c|c|c|c|c|c|}
\hline Source & DF & Seq SS & Adj SS & Adj MS & $F$ & P & Contribution \\
\hline $\mathrm{A}$ & 1 & 129.322 & 129.322 & 129.322 & 4.84 & 0.079 & $51.22 \%$ \\
\hline $\mathrm{B}$ & 1 & 0.144 & 0.144 & 0.144 & 0.01 & 0.944 & $0.06 \%$ \\
\hline $\mathrm{C}$ & 1 & 112.254 & 112.254 & 112.254 & 4.20 & 0.096 & $44.46 \%$ \\
\hline $\mathrm{D}$ & 1 & 10.778 & 10.778 & 10.778 & 0.40 & 0.553 & $4.27 \%$ \\
\hline $\mathrm{A}^{*} \mathrm{~B}$ & 1 & 139.831 & 139.831 & 139.831 & 5.23 & 0.071 & \\
\hline $\mathrm{A}^{*} \mathrm{C}$ & 1 & 79.531 & 79.531 & 79.531 & 2.98 & 0.145 & \\
\hline $\mathrm{A}^{*} \mathrm{D}$ & 1 & 25.482 & 25.482 & 25.482 & 0.95 & 0.374 & \\
\hline $\mathrm{B}^{*} \mathrm{C}$ & 1 & 4.170 & 4.170 & 4.170 & 0.16 & 0.709 & \\
\hline $\mathrm{B}^{*} \mathrm{D}$ & 1 & 16.419 & 16.419 & 16.419 & 0.61 & 0.469 & \\
\hline $\mathrm{C}^{*} \mathrm{D}$ & 1 & 5.929 & 5.929 & 5.929 & 0.22 & 0.657 & \\
\hline Residual Error & 5 & 133.589 & 133.589 & 26.718 & & & \\
\hline Total & 15 & 657.449 & & & & & $100 \%$ \\
\hline
\end{tabular}

formed into each noise factor and control factor. ANOVA or analysis of variance is used to find the significance of the effects of each control parameter in a process. The magnitude of this effect can be determined by comparing the sum of the squared values of the control parameters against all control parameters. In other words, the variance between analyses is a technique that enables calculations to estimate the contribution to each factor quantitatively to all response measurements. Analysis of variance was used in the design parameters for helping to identify the contributing factors to estimate the accuracy of the model can be determined illustrated Table 10.

Table 10 presented that program and method parameters are significant variables positively affecting the variable thickness of the powder coating. This can be typically identified by the P-value of less than $5 \%$. $(P<5 \%)$. For the valuable present, the used variable $\mathrm{C}$ efficiently is, a user variable that does not significantly affect the variable thickness of the powder coating $(P>5 \%)$. The percent contributions of powder coating parameters on coating thickness average are provide in table 10. Program and method contribute for $95.67 \%$ of thickness average. The effect of distance is more pronounced in case of thickness average with a contribution of $4.27 \%$ of thickness average while distance parameter has very less contribution.

Interaction plotted parameters that significantly affect the direct response to powder coating thickness efficiently is $A^{*} B, A^{*} C, B^{*} C$, and $B^{*} D$. While the interaction parameters that do not significantly affect the direct response precious are $A^{*} D$ and $A^{*} C$. The practical application of the $20-\mathrm{cm}$ distance parameter has a light significant increase in thickness response to the level increase of the layer parameter. In the $20-\mathrm{cm}$ distance parameter, the marked increase in thickness response that particularly occurs is not significant enough. Interaction plot of $C * D$ (method $x$ number of layers). The practical application of the vertical-horizontal and vertical method variables for typically increasing the optimal level of the consid- erable number of active layers typically occur on which increases the thickness response which is not extremely significant.

\section{Confirmation test}

The confirmation test is the final step in the first iteration of the design of the experiment process. The purpose of the confirmation test is to validate the conclusions drawn during the analysis phase [2]. This is performed by conducting a test with a specific combination of the parameters and levels previously evaluated. In this study, after determining the optimum conditions and predicting the response under these conditions, a new experiment was designed and conducted with the optimum levels of the powder coating process parameters. The results of experimental confirmation using optimal powder coating parameters and comparison of the predicted coating thickness with the actual coating thickness using the optimal powder coating process parameters are shown in Table 11

\section{Table 11: Result of confirmation experiment}

\begin{tabular}{|c|c|c|c|c|}
\hline \multirow{2}{*}{$\begin{array}{l}\text { Descrip- } \\
\text { tion }\end{array}$} & \multirow{2}{*}{$\begin{array}{l}\text { Initial } \\
\text { process } \\
\text { factors }\end{array}$} & \multicolumn{2}{|c|}{$\begin{array}{l}\text { Optimal process } \\
\text { factors }{ }^{4)}\end{array}$} & \multirow{2}{*}{$\begin{array}{l}\text { Improve- } \\
\text { ment in } \\
\text { S/N ratio } \\
(\%)\end{array}$} \\
\hline & & $\begin{array}{l}\text { Predict- } \\
\text { ed }\end{array}$ & $\begin{array}{l}\text { Experi- } \\
\text { mental }\end{array}$ & \\
\hline Level & $\begin{array}{l}\mathrm{A} 1 ; \mathrm{B} 1 ; \\
\mathrm{C} 1 ; \mathrm{D} 1\end{array}$ & \multicolumn{2}{|c|}{$\mathrm{A} 1 ; \mathrm{B} 1 ; \mathrm{C} 2 ; \mathrm{D} 2$} & \multirow{3}{*}{$6.96 \%$} \\
\hline $\begin{array}{c}\text { Thick- } \\
\text { ness } \\
\text { average } \\
(\mu \mathrm{m})\end{array}$ & 42.41 & 76.08 & 84.85 & \\
\hline $\begin{array}{l}\mathrm{S} / \mathrm{N} \\
\text { Ratio }\end{array}$ & 35.83 & 37.08 & 38.32 & \\
\hline
\end{tabular}




\section{CONCLUSION}

The experimental results properly indicated the most significant effect on the variant response efficiently was the method variable which has a delta value of 0.91 . It was properly followed by three other factors, namely: program, a variable number of layers and distance with the delta value are $0.83,0.37$ and 0.2 respectively. These are consistent with the highest average thickness data has achieved, 84.85 microns which were reasonably achieved in the fourth iteration. This optimal condition was achieved precisely at program 01, a 20-cm proper distance, vertical-horizontal method and the number of layers is four times. Empirical research has provided a solution to the optimization of powder coating variables so that the effective response to powder coating thickness can be improved remarkably. In keeping the excellent consistency of the considerable influence of four independent variables on the response variable, further research will be conducted on another specific material, namely polyester TGIC powders coatings.

\section{ACKNOWLEDGMENT}

The authors are grateful to Sekolah Tinggi Teknologi Wastukancana and Universitas Buana Perjuangan Karawang for financial supported.

\section{REFERENCES}

1. Du, Zhongyan, et al. The review of powder coatings. Journal of Materials Science and Chemical Engineering, 2016, 4.3: 54-59.

2. Mirabedini, S. M.; Kiamanesh, A. The effect of micro and nano-sized particles on mechanical and adhesion properties of a clear polyester powder coating. Progress in Organic Coatings, 2013, 76.11: 16251632.

3. Hadavand, Behzad Shirkavand; Ataeefard, Maryam; Bafghi, Hamed Fakharizadeh. Preparation of modified nano $\mathrm{ZnO}$ /polyester/TGIC powder coating nanocomposite and evaluation of its antibacterial activity. Composites Part B: Engineering, 2015, 82: 190-195.

4. Utech, Bob. A guide to high-performance powder coating. Society of Manufacturing Engineers, 2002.

5. Japanese Standards Association, JIS G 3141 Cold-reduced carbon steel sheets and strip. 2005.

6. Funke, Wi. Problems and progress in organic coatings science and technology. Progress in Organic coatings, 1997, 31.1-2: 5-9.

7. Zouari, Manel, et al. Scratch resistance and tribological performance of thermosetting composite powder coatings system: A comparative evaluation. Surface and Coatings Technology, 2015, 263: 27-35.

8. Shinde, Rakesh A.; Patil, Bhushan T.; Joshi, Ketaki $\mathrm{N}$. Optimization of tube hydroforming process (without axial feed) by using FEA simulations. Procedia Technology, 2016, 23: 398-405.
9. Neubauer, Dean. Process Optimization: A Statistical Approach. 2008.

10. Cerea, Matteo, et al. A novel powder coating process for attaining taste masking and moisture protective films applied to tablets. International journal of pharmaceutics, 2004, 279.1-2: 127-139.

11. Rahul, S. H.; Balasubramanian, K.; Venkatesh, Sriram. Optimizing inkjet printing process to fabricate thick ceramic coatings. Ceramics International, 2017, 43.5: 4513-4519.

12. Haanappel, V. A. C., et al. Optimisation of processing and microstructural parameters of LSM cathodes to improve the electrochemical performance of anode-supported SOFCs. Journal of Power Sources, 2005, 141.2: 216-226.

13. Porter, Stuart; Sackett, Gary; Liu, Lirong. Development, optimization, and scale-up of process parameters: pan coating. In: Developing solid oral dosage forms. Academic Press, 2017. p. 953-996.

14. Ramlakhan, Michelle, et al. Dry particle coating using magnetically assisted impaction coating: modification of surface properties and optimization of system and operating parameters. Powder Technology, 2000, 112.1-2: 137-148.

15. Cahyadi, Christine; Heng, Paul Wan Sia; Chan, Lai Wah. Optimization of process parameters for a quasi-continuous tablet coating system using design of experiments. Aaps Pharmscitech, 2011, 12.1: 119131.

16. Bose, Sagarika; Bogner, Robin H. Solventless pharmaceutical coating processes: a review. Pharmaceutical development and technology, 2007, 12.2: 115-131.

17. Sivapragash, M., et al. Taguchi based genetic approach for optimizing the PVD process parameter for coating ZrN on AZ91D magnesium alloy. Materials \& Design, 2016, 90: 713-722.

18. Thakur, A. G.; Nandedkar, V. M. Optimization of the resistance spot welding process of galvanized steel sheet using the Taguchi method. Arabian Journal for Science and Engineering, 2014, 39.2: 1171-1176.

19. Mahmud, K. H., Yudistirani, S. A., Ramadhan, A. I.. Analysis Of Hardness Of Material Connection Of Weld On The Effect Of Air Humidity. International Journal of Scientific \& Technology Research, 2018,7.2: 90-93.

20. Haidopoulos, M., et al. Development of an optimized electrochemical process for subsequent coating of 316 stainless steel for stent applications. Journal of Materials Science: Materials in Medicine, 2006, 17.7: 647-657.

21. Bose, Sanjukta, et al. Process optimization of ultrasonic spray coating of polymer films. Langmuir, 2013, 29.23: 6911-6919. 
22. Chiang, Chien-Hung; Tseng, Zong-Liang; Wu, ChunGuey. Planar heterojunction perovskite/PC 71 BM solar cells with enhanced open-circuit voltage via a (2/1)-step spin-coating process. Journal of Materials Chemistry A, 2014, 2.38: 15897-15903.

23. A. Abdulah, S. Sukarman, C. Anwar, A. Djafar Shieddieque, and A. I. Ramadhan, Optimization of yarn texturing process DTY-150D/96F using taguchi method, Technology Report of Kansai University, 2020, 62.4: 1471-1479,.
24. Sukarman, Sukarman, et al. Optimization of Tensile-Shear Strength in the Dissimilar Joint of Zn-Coated Steel and Low Carbon Steel. Automotive Experiences, 2020, 3.3: 115-125. 